\title{
CANDID CAMERA? (DA PRESENÇA E USOS DO FOTOGRÁFICO EM ALGUMA POESIA PORTUGUESA CONTEMPORÂNEA)
}

\author{
Paulo Alexandre Pereira \\ (Universidade de Aveiro - Portugal)
}

\section{RESUMO}

No presente artigo, examina-se a presença e funcionalidade do paradigma fotográfico em alguma poesia portuguesa contemporânea, procurando-se ilustrar a diversidade das suas incidências ideotemáticas e das estratégias de composição poética que com ele se conexionam.

PALAVRAS-CHAVE: fotografia; poesia portuguesa contemporânea; écfrase.

\begin{abstract}
This article aims to examine the presence and functions of the photographic paradigm in some Portuguese contemporary poetry, so as to shed some light both on its thematic diversity and on the strategies of poetic composition encompassed by it.
\end{abstract}

KEYWORDS: photography; Portuguese contemporary poetry; ekphrasis 
Depois de, no decurso do seu ensaio sobre A novíssima poesia portuguesa e a experiência estética contemporânea, sublinhar a "omnipresença generalizada de pixels" precipitada pela inflação contemporânea de imagens na desnorteante iconosfera contemporânea, Luís Carmelo regista, nos seguintes termos, o recuo da inscrição do paradigma fotográfico na recente poesia portuguesa: "A contemporaneidade digital já quase não permite a existência de formas verosímeis e tradicionais de imagem, como, por exemplo, a fotografia. Hoje em dia, fotografar é quase só já suspender o fluxo ininterrupto de imagens que atravessa a globalizada rede das redes" (CARMELO, 2005, p. 115). E, um pouco adiante, acrescenta:

Isto significa que a poesia contemporânea portuguesa - como outras poesias do nosso tempo - acompanha a contemporaneidade, é certo, mas, ao mesmo tempo, também dela se distancia com a mesma compaixão existencial que a fotografia não digital - a da revelação na câmara-escura, a da antiga photogenie fantasmática - demonstra nos nossos dias. Este ideal de antecâmara sobrevivente é um dos requisitos de alguma arte (quase "neo-utópica" que ainda vai subsistindo ao lado da esteticização generalizada e hipertecnológica do "globário". (CARMELO, 2005, p. 116)

Ora, um sobrevoo mesmo desprevenido por alguma poesia contemporânea parece antes substanciar a suspeita de que, a contracorrente da hegemonia do digital, esse "ideal de antecâmara generalizada", reconduzível a uma subsistente herança analógico-fotográfica, continua a inscrever-se, num continuum ininterrupto e multímodo, na criação lírica contemporânea ${ }^{1}$. Pretendo, pois, demonstrar, no presente ensaio, como essa presença axial do imaginário fotográfico ${ }^{2}$ excede, em muitos casos, o plano da estrita tematização, instituindo-se como rendoso dispositivo formalizante do próprio fazer poético, com significativas repercussões tanto ao nível da sobredeterminação de sentido, como da dispositio textual. Não será redundante, também neste contexto, relembrar, com Susan Sontag, que as fotografias fundam "(...) a grammar and, even more importantly, an ethics of seeing” (SONTAG, 2008, p. 3), porquanto se tratará aqui de dilucidar os contornos do que poderia, ainda tentativamente, designar-se como uma epistemologia poética do fotográfico.

Esclareço, desde logo, que o corpus poético a analisar, coesionado em torno da inscrição plurifuncional do fotográfico em cotexto lírico, não obedece a outro critério que não o da estrita conveniência ilustrativa, decorrendo, além disso, da convocação de um critério supletivo - assumidamente lábil, mas operatório para o que aqui me ocupa - de contemporâneo, recobrindo um arco temporal que se estende de Ruy Belo a Pedro Mexia. Se insisto neste aspeto é porque pretendo deixar claro que a aproximação da versatilidade retórico-imaginária do topos fotopoético que aqui se ensaia 
não tem em vista uma caracterização transversal da poiesis singular de nenhum dos autores considerados, nem a prospeção diacrónica de constantes periodológicas, embora possa, colateralmente, ajudar a esclarecê-las.

\section{2.}

Não parece surpreendente que o elenco de poemas selecionado, por neles explicitamente se encontrarem textualizadas as possibilidades e limites do diálogo transmedial com o fotográfico, apresentem entre si a afinidade acrescida de concederem particular destaque temático a questões de poiesis, sobretudo as que se prendem com a representação e a memória. As homologias entre a focalização lírica do mundo e a (falsa) transparência do olhar fotográfico têm, aliás, sido insistentemente salientadas, em particular no contexto das poéticas modernistas. Anne Reverseau observa, a este respeito, que "à l'époque moderniste, la notion de regard et l'influence de la photographie vont de pair avec le retour de la question de la réalité et de la mimesis en poésie" (REVERSEAU, 2008, s.p.). E Susan Sontag, detendo-se ainda na linhagem poética modernista, acentua o que nela parece acercá-la da ética-estética do olhar intensivo preceituada pela fotografia:

Poetry's commitment to concreteness and to the autonomy of the poem's language parallels photography's commitment to pure seeing. Both imply discontinuity, disarticulated forms and compensatory unity: wrenching things from their context (to see them in a fresh way), bringing things together elliptically, according to the imperious but often arbitrary demands of subjectivity. (SONTAG, 2008, p. 96)

Desenvolvido a partir da oscilação pendular entre pictoralismo e deriva subjetiva - também neste caso, imperiosa e arbitrária -, o poema "Solene saudação a uma fotografia", de Ruy Belo, parece-me constituir modelar ilustração das palavras da ensaísta de On Photography. Escandido ao ritmo do "regime diferenciado da anáfora" (GUSMÃO, 2010, p. 431), numa tensão produtiva entre discursividade e visualidade, o texto de Ruy Belo articula-se como uma elegia distendida, sob a forma de nostálgica evocação de uma figura feminina que a descoberta inopinada de uma fotografia - "ali perdida na fotografia/ entre diapositivos e agendas caixas de comprimidos/ botões de punho livros algodão sobre a mesa-de-cabeceira" (BELO, 2000, p. 322) - faz deflagrar: "E de novo de súbito a helena viva aqui nesta fotografia" (BELO, 2000, p. 320). Neste incipit pode ler-se uma espécie de cena poética primitiva que inúmeros textos líricos de incidência fotoimaginária irão insistentemente retextualizar. Neste núcleo generativo terá que incluir-se o motivo tópico da fotografia acidentalmente descoberta por entre papéis avulsos, objet trouvé catalítico, de nítido valor lírico-inceptivo. Em virtude do seu punctum interpelante, a fotografia, de presença assídua nesta mise-en-scène preambular, constitui, para a instância focalizadora, um irresistível catalisador mnésico, desencadeando a ars memora- 
tiva e marcando o compasso reminiscente e digressivo do texto. No poema de Ruy Belo, esse diaporama íntimo, pontuado de fluxos e refluxos da memória e declinado segundo uma arbitrária gramática associativa, vai de par com a ficção de desmolduramento que funda o poema: com efeito, mesmo ausente, a figura de helena encontra-se "viva aqui numa fotografia", como se a dinâmica presentificadora e o factício represamento do tempo por ela propiciados lhe permitissem, por instantes, exorbitar a moldura e "sair do labirinto desse verão onde a deixei” (BELO, 2000, p. 321). Porque, pela mobilização desse efeito de desenquadramento, se dá a ver a figura feminina provisoriamente rediviva aos olhos do observador, a fotografia anima-se para retratar a "mulher coisa mudável", nas suas cambiantes fisionómicas e emocionais. Não é acidental que a convocação decetiva de um "tempo detergente que nos lava que nos leva” - contra cuja socializada opressão se recorta a imagem incorrompida de uma "helena natural" - assuma uma coloração elegíaca que, na discreta disforia subliminar do poema, se abate sobre toda a "morte implícita no tempo" (BELO, 2000, p. 320).

Consciente do impulso degradador que preside a toda a temporalidade, não deixa o poeta-fotógrafo de, no duplo analógico de uma "helena viva", pressentir o regresso do morto anunciado por Roland Barthes:

E aquele ou aquilo que é fotografado é o alvo, o referente, uma espécie de pequeno simulacro, de eidôlon emitido pelo objecto, a que poderia muito bem chamar-se o Spectrum da Fotografia, porque esta palavra conserva, através da raiz, uma relação com o "espetáculo" e acrescenta-lhe essa coisa um pouco terrível que existe em toda a fotografia: o regresso do morto. (BARTHES, 2010, p. 17)

Como muito justamente assinalou já Pedro Serra, a propósito da aliança de imaginação fotográfica e experiência da temporalidade na poética de Ruy Belo, "o tempo que é essencialmente alterizante é agente da sua constante destruição. Por outras palavras, se no tempo as coisas - e os seres - exibem a sua mortalidade, na palavra fotográfica contrapõem-se a esta lógica mortal” (SERRA, 2004, p. 93) ${ }^{3}$. Nos interstícios da rememoração jubilatória de um passado que, por semelhança com a personagem evocada, se descobre, cada vez mais, "definitivamente ausente", "inacessível" e "inexpugnável” (BELO, 2000, p. 321), em "Solene saudação a uma fotografia” intromete-se já a experiência aporética do tempo fotográfico que mumifica o passado numa "imobilidade amorosa ou fúnebre, no próprio seio do mundo em movimento" (BARTHES, 2010, p. 13).

Também em "Um Verão Quente”, de Fernando Luís Sampaio, a qualidade cinética da fotografia em metamorfose (onde, muito cinematograficamente, "o lenço/ de uma brancura galopante/ começa a desaparecer") subverte a inalterabilidade do registo, também ele submetido à lei irreversível da desmemória: 
Há uma fotografia em que estás

triste, o dourado dos anos desmaiado,

é em Madrid, suponho que no inverno. (...)

$\mathrm{Na}$ fotografia, ainda triste, o lenço

de uma brancura galopante

começa a desaparecer. (SAMPAIO, 2000, p. 46)

A um tempo vitória do efémero e momento mori ${ }^{4}$, hino e elegia, phantasma e vestigium, a fotografia suspende o instante, intimando paradoxalmente, nessa preensão imobilizadora, a sua mortalidade. Ora, é justamente este paradoxo que justifica a persistente investigação poética da fratura pressentida entre o momento pregnante do kairos fotográfico e os efeitos do tempo erosivo e corruptor, numa refontalização dos loci clássicos do tempus fugit e do mundus senescit, em torno dos quais se aglomera um amplo repertório de metáforas de decomposição e desgaste. É o que acontece, por exemplo, no texto "Quase luz nenhuma" de Al Berto, integrado na série poética dedicada ao fotógrafo Paulo Nozolino, onde se ratifica que "em todos os retratos haverá um rastro de ferrugem/ porque a demora corrói o olhar" e se confessa "o receio/ de mais tarde olhar as fotografias e já não sentir/ pulsar no papel vida nenhuma” (AL BERTO, 1991, p. 320), assim como em versos colhidos numa das sequências de "Rumor dos Fogos": "o mundo que te rodeou continua inaudível e perdido/ apodrece nas fotografias arrumadas dentro da gaveta/ debaixo da roupa arrumada" (AL BERTO, 1991, p. 332). Essa cumplicidade ingénita de memória (fotográfica) e fotografia (mnésica) - e é, precisamente, ela que explica que, no arquivo experiencial privado, se deposite, em versão magnificada, aquilo de que a fotografia constitui um simulacro em tom menor - aparece tematizada, com contornos de programa poético, em "Câmara Escura", de Ana Luísa Amaral:

São assim as memórias: coisas cheirando a sol, outras a morte, algumas a pequenos sons metálicos que convém afinar $[\ldots]$

Cofre guardado muito mais que em cor, velocidade em teor do universo, de precisão tão mais que a fotografia. (AMARAL, 2005, p. 265)

A tentativa de captura paralisante do momento subjacente ao ato fotográfico e o seu gesto inaugural de stasis apropriadora aproximam-na, 
como notou R. Barthes, do tableau vivant: "Na Fotografia, a imobilização do Tempo só se apresenta de um modo excessivo, monstruoso: o Tempo é sustido (daí a relação com o Quadro vivo, cujo protótipo mítico é o adormecimento da Bela Adormecida" [BARTHES, 2010, p. 101]). Por isso, o seu empenho reificante é invariavelmente assombrado pela intimação espectral do que já não é. Dito de outro modo, no gesto de musealização privada que a fotografia supõe e na gramática da pose que a regula ${ }^{5}$ torna-se inteligível não tanto a remanescência, mas, de modo mais conspícuo, a irrecuperabilidade de um passado cristalizado em versão liofilizada. No poema "Sorrisos", de Ana Luísa Amaral, embora a imunidade ao tempo erodente pareça protelar o insustível desvanecimento do que um dia foi experiência eufórica, torna-se iniludível que a "suspensa hibernação" fotográfica apenas dela consegue devolver um resto precário e empobrecido, como aliás não deixa de insinuar a prodigiosa metáfora - por isso, também oximoro - que remata o texto e por meio de cuja lapidar concisão se define a fotografia como "um comovido glaciar de luz":

\author{
O sorriso \\ retido por fotografia: \\ esse ponto cadente \\ em que músculos mil fazem rodar \\ à velocidade mínima de estrela: \\ a boca, a face, o canto \\ do olhar (...)
}
O laço para sempre
inviolado
que se retém numa fotografia:
imune a tempo,
à velocidade máxima da vida,
ao julgado infinito
desamor

Suspensa hibernação
do ponto que foi
estrela,
do canto do olhar que foi
canção maior:
um comovido glaciar
de luz (AMARAL, 2005, p. 130)

É ainda a funda consubstancialidade entre fotografia e finitude que, no poema "Fotografia" de Nuno Júdice, polariza a meditação lírica dinamizada pela contemplação de "um nu sulfuroso de arget" (JÚDICE, 2010, p. 119) ${ }^{6}$. O sumário segmento ecfrástico que inicia o poema - onde, em registo de sereno pictoralismo replicativo, se esboça a descriptio da figu- 
ra feminina - logo se ramifica em atalhos filosófico-indagativos que, com efeito, constituem o seu real centro de gravitação semântica. Revelam-se, pois, neste contexto, especialmente pertinentes as palavras de R. Barthes, quando argumenta que "no fundo, a Fotografia é subversiva não quando assusta, perturba ou até estigmatiza, mas quando é pensativa" (BARTHES, 2010 , p. 47). Neste caso, em rigor, o estímulo fotográfico não disponibiliza um rastilho ecfórico ou um pretexto instrumental para uma expedição arqueológica pelo passado. É, antes, na especulação desenvolvida a partir da cenografia contemplada (ou, talvez melhor, para além dela) - designadamente a plausibilidade de "aquela/ mulher, hoje, não passa[r] de cinza nalgum canto/ de cemitério de província” (JÚDICE, 2010, p. 119) - que se irá fazer entroncar a coda decetiva onde se glosa a efemeridade da vida. Enquanto "emanação do referente" (BARTHES, 2010, p. 91), a contemplação da fotografia impulsiona, no poema de Nuno Júdice, um movimento centrípeto de recuo introspetivo, devolvendo o sujeito à consciência inquietante da sua própria mortalidade e, por essa via, refratando a sua natureza contingente e temporal. Essa dinâmica de recentramento íntimo encontra a sua concreção figurativa na evanescência da sépia que dissolve o sorriso da mulher que "se esbate com/ essa espécie de névoa com que o tempo envolve/ as fotografias antigas" (JÚDICE, 2010, p. 119), num evidente reenvio para a fragilização do poder referencial da fotografia. Ao dizer a nudez que "desafia a morte", o sujeito diz da sua própria nudez perante a morte, num jogo de comutação fenomenológica entre observador e coisa observada, em função do qual, partindo do silêncio eloquente da fotografia, se instaura uma dialética projetiva de alterização e ipseidade. Se todo o retrato é um autorretrato, também o fotógrafo se transforma, até certo ponto, na coisa fotografada. Talvez por isso, nos poemas em que o sujeito se encontra implicado na observação de fotografias, o gesto contemplativo coexista, com sintomática constância, com a enunciação de um pathos melancólico que parece transcorrer de uma difusa sensação de epigonismo ou da suspeita de ser chegado o "tempo do pó", como se pode ler em "Retrato", de José Agostinho Baptista:

Neste retrato eras tu - e não poderia ser eu? com o tempo por cima, a passar impiedosamente, o tempo do declínio, o tempo do pó, tudo o que hoje se comprime nesta moldura de prata, ao centro da mesa tristemente. (BAPTISTA, 2000, p. 599)

Desta mesma retórica de epicédio participa o microrrelato ${ }^{7}$ de recorte elegíaco desenvolvido em "Um retrato dos meus tios Pedro e João na parede da sala”, de Pedro Mexia. O título do poema evoca, por transparente catáfora, a contemplação ritual de um desses "altares domésticos"8 (ROSA, 2008, p. 14) onde se encontram expostas fotografias familiares de ocasião 
e permite antecipar o arranjo memorial das experiências nele arquivadas. Também aqui, a inspeção comovida e desesperançada dos efeitos dissolventes do tempo e da inevitável desfocagem por ele ditada se inscrevem na materialidade pictórica do retrato que "tem o tom sépia dos retratos de então" e "[se] esboroa, de pó e cal, como a parede" (MEXIA, 2011, p. 44). A intuição lúcida dessa vertigem de desagregação - que, em qualquer caso, não obsta ao confronto iluminante do observador com um "tempo de revelação" autobiográfica - é, paradoxalmente, amparada pela recomposição quase microrrealista de um quotidiano trivial que, a distância, ajuda a escandir um tempo que se sabe irremediavelmente extinto:

Há outras fotografias onde estão juntos, mas nesta são crianças, e sendo crianças é como se não fossem diferentes, é como se tivéssemos todos veraneado juntos na Figueira, onde a água é fria e o mar está muito ao fundo da praia, e as famílias se podem sucessivamente repetir, geração após geração, conhecendo-se e passeando um pouco depois do jantar.

(MEXIA, 2011, p. 44-45)

Conexamente, o olhar transfigurante do observador opera uma espécie de trucagem mental da fotografia familiar, reconfigurando imaginativamente a substância deítica da imagem pela instituição de uma ilusão de vivido. Este olhar desfuncionaliza, deste modo, o que Barthes, a propósito da referência fotográfica, designa como o "noema da fotografia": "Chamo 'referente fotográfico' não à coisa facultativamente real para que remete uma imagem ou um signo, mas à coisa necessariamente real que foi colocada diante da objectiva sem a qual não haveria fotografia. (...) O nome do noema da Fotografia será então 'Isto-foi' ou, ainda, o Inacessível" (BARTHES, 2010, p. 87). Ora, parece-me ser à luz deste deslocamento do que foi para o que podia ter sido que pode interpretar-se a "fotografia apócrifa", retocada in mente pelo sujeito, que, na fotografia real que, com efeito, observa, decide extemporaneamente intrometer-se: "Tenho uma fotografia com ele/ e penso que se calhar estou com ele na fotografia como/ se fôssemos da mesma idade e estivéssemos/ na Figueira de 1930, e a ideia magoa tanto/ que perde toda a possibilidade de ser jubilosa"; "O retrato do meu tio João e do meu tio Pedro/ que está na parede da sala representa a hipótese/ de estarmos no retrato que, apesar disso,/ nos escapa infinitamente" (MEXIA, 2011, p. 45) ${ }^{9}$. Estes versos poderiam, assim, entender-se como exemplar contraparte lírica das considerações expendidas por R. Barthes, quando examina o presumível ethos nostálgico da fotografia. Para o autor de A câmara clara,

A Fotografia não diz (forçosamente) aquilo que já não é, mas apenas e de certeza aquilo que nunca foi. Esta subtileza é decisiva. Diante de uma foto, a consciência 
não segue necessariamente a via nostálgica da recordação (quantas fotografias não estão fora do tempo individual), mas, para toda a fotografia existente no mundo, a via da certeza: a essência da Fotografia é ratificar aquilo que representa. (BARTHES, 2010, p. 95).

Essa impregnação melancólica da silente superfície fotográfica ${ }^{10}$, tornada inadiável pela "necessidade desesperada/ de ler coisas neste retrato, para que ele não emudeça/ de vez" (MEXIA, 2011, p. 45) ${ }^{11}$, não ignora os processos de framing e de recorte que enformam a sintaxe fotográfica. No transcurso dos seus ensaios sobre fotografia, Susan Sontag lembra que "the photograph is a thin slice of space as well as time", acrescentando que "in a world ruled by photographic images, all borders ('framing') seem arbitrary" (SONTAG, 2008, p. 22) e desse dispositivo de editing visual revela apurado entendimento o sujeito poético no texto de Pedro Mexia, que bem sabe que a objetiva da câmara, absolutamente indiferente ao que fotografa, condiciona a composição seletiva e fragmentária do vivido, a partir da qual apenas pode pressentir-se a ausência fantasmática do irrepresentado:

o fotógrafo certamente faz gestos, diz coisas, mas isso está para lá da fotografia, e nunca se há-de saber. Não terá ficado tudo perdido como o gesto do fotógrafo, como a sua voz pedindo o sorriso, olhó passarinho, no tempo da exposição a que tem de seguir-se, mais cedo ou mais tarde, o da revelação?

(MEXIA, 2011, p. 44)

Parece, portanto, indiscutível que, para o poeta-fotógrafo que se autorrepresenta como colecionador de imagens e emoções, a "estenografia visual" (SONTAG, 2008, p. 48) da fotografia tende, por transporte deítico, a reativar um thesaurus afetivo e experiencial mais ou menos distante, mas, em qualquer caso, subsumível à sua história passada. Por vezes, contudo, este tropismo regressivo do fotograma lírico parece inseparável de uma representação topicalizada do tempo, desenhando-se então uma cartografia lírica, afetiva ou simbolicamente tonalizada, sem contudo rasurar a sua funda radicação temporal. No poema "Me and my brother", de José Tolentino Mendonça, a reconstituição do cronótopo da infância, impulsionada pela observação da fotografia, não prescinde do mapeamento lírico dos lugares diletos desse tempo arcaico, conjugando-o com a recuperação estilizada da tradição retórica do ubi sunt:

Percorria os lugares daquela fotografia a muralha de silvas, a quinta reencontrada os finais de ano e aquilo que depois não está onde antes existiu 
Singularmente discorde desta orquestração nostálgica, o poema "Antevisão", de Fernando Pinto do Amaral amplia, vertendo-a no molde da quadra pseudopopularizante, a isotopia da alma como "imperfeita câmara escura", nela se revelando não a autobiografia residual do vivido, mas as "cenas/ de uma vida futura" (AMARAL, 2000, p. 487). Esta projeção, em flashforward, de películas imaginárias engendra, como o próprio sujeito lírico bem reconhece, "Fotografias no avesso/ da consciência fugidia", que se sucedem num ecrã de utópica e desejante idealidade, onde parece entreouvir-se a tutelar conviç̧ão pessoana de que "essa coisa é que é linda":

\author{
Fotografias no avesso \\ da consciência fugidia \\ hão-de exigir-nos o seu preço \\ para a melancolia, \\ mas é tão bom ficar a vê-las \\ dentro de nós num céu fictício \\ onde cintilam as estrelas \\ desse puro artifício
}

iluminando a nossa treva

com a estranha luz de um sobressalto

e é talvez isso que nos leva

a um lugar mais alto. (AMARAL, 2000, p. 487)

Noutros textos, que conformam sumárias alegorias de alcance metapoético, o referente fotográfico converte-se em ersatz do ato de criação, ajudando a esclarecer, por prolongamento especular ou diferença contrapontística, a génese do poema. Em "Leica", de Al Berto, a homologia, desde logo prefigurada pela escolha titular, entre os universos da escrita e da fotografia traduz-se na equivalência funcional entre os códigos da palavra e da luz, tornando claro o intencional aceno metalinguístico à memória etimológica da fotografia como escrita de luz: "é preciso muito pouca luz para definir um rosto/ poucas palavras para que o fascínio desse segundo/ torne possível dormir dentro da máquina fotográfica" (AL BERTO, 1991, p. 322)

Em "Fotografia de mulher num molhe", de Nuno Júdice, a interrogação autorreflexiva sobre a matéria-prima do poema - "O vocabulário da experiência constrói o poema,/ pedra a pedra, somando o que se diz que é a vida/ ao que dela dizemos" (JÚDICE, 2006, p. 80) - evoca, por analogia, a silenciosa completude da fotografia. A impossibilidade de ingerência do poeta no heterocosmos visual da eloquens pictura - sendo, portanto, incapaz de transformá-la - duplica, em negativo, o aleatório devir do poema: "Eu diria que, entre a mulher e o bosque, correm/ as águas do poema. Não sei dizer de onde/ vem o seu curso, nem qual o estuário em que/ desagua (...)" (JÚDICE, 2006, p. 80). 


\section{3.}

Também no plano retórico-processual, estas fotografias verbais tornam patente, pelo recurso a estratégias formalizantes ou particulares rasgos de dicção, o seu estatuto semiótico transicional. Antes de mais, como já antes se acentuou, são pedidos de empréstimo à sintaxe fotográfica os dispositivos poéticos de edição ${ }^{12}$ - focagem e enquadramento - quase sempre inseparáveis da modalização dubitativa que pontua a evocação. Ao efeito-moldura - que, no móbil fotográfico, procura um enquadramento ficcional fundador da descrição - aliam-se, assim, os procedimentos de desfocagem por intermédio dos quais se mimetiza a falibilidade da memória. O topos da desfocagem - a que não será estranha uma predileção fin-de-siècle pelo evanescente e pelo difuso - deteta-se, por exemplo, em inúmeros textos de Nuno Júdice, em que a legibilidade visual das fotografias se afigura incerta ou até conjetural. Ilustro com versos colhidos em "Retrato de adolescente" (de Cartografia de Emoções) e "Fotografia branca" (de As coisas mais simples):

\section{(...) A fotografia em que estou} contigo, e onde estás desfocada com o fumo e a luz fraca do candeeiro de cima, ainda me traz a tua inquietação: um outro sinal da época. (Júdice, 2001, p. 148)

(...) tu, sentada à mesa, para que eu te pudesse fixar com a nitidez do fotógrafo, olhas-me, como se eu estivesse à tua frente; $\mathrm{e}$ o teu olhar apaga o tempo e a distância, desfocando a imagem, como se o fumo do cigarro te envolvesse o rosto, $\mathrm{e}$ te trouxesse de volta a mim, como nuvem, ou sonho, que o vento dissipa. (JÚDICE, 2006, p. 27)

Em “fotografia”, de Vasco Graça Moura, a ruína material do registo fotográfico - formulada em termos que parecem reminiscentes do fantástico retrato do Dorian Grey wildeano - constitui o correlativo objetivo do escoamento da energia erótica, transposto para a imagem "sem disfarce" de quem outrora se amou. É a "imagem a apagar-se" que a fotografia, desmaiada e corroída pela luminosidade excessiva, agora devolve:

não é só na fotografia

a tua imagem a apagar-se:

é muito mais o que eu não via

e surge agora sem disfarce.

a sombra alastra. Principia

cada feição a evaporar-se

porque a emulsão já se arrepia

na cor a deteriorar-se 
da muita luz que lhe sobrou

destemperadamente rude,

como um excesso desse agosto. (MOURA, 2000, p. 19)

Embora, em alguns destes textos, a fotocomposição poética se encontre flagrantemente próxima do paisagismo impressionista ou da plasticidade estática da natureza morta, não é raro que neles aflore uma consistente narratividade, subsumível tanto à vontade efabulatória instigada pela contemplação da fotografia única e irrepetível, como à sua colagem serial num álbum cuja sintaxe aditiva permite recompor um descontínuo relato fotobiográfico. Concatenadas no álbum, as fotografias consubstanciam parcelas biográficas que, em inesperada coligação, permitem retraçar uma intermitente história de vida pessoal ou familiar, sempre mediada pelo "inconsciente ótico" (BENJAMIN, 2000, p. 301) ${ }^{13}$ do seu autor.

É em sintonia com essa disposição de fotomontagem surrealizante - aliás, como sustenta Susan Sontag, "any collection of photographs is an exercise in Surrealist montage and the Surrealist abbreviation of history" (SONTAG, 2008, p. 68) ${ }^{14}$ - que, no poema "Álbum de Família", de Luiza Neto Jorge, são intimadas as figuras do círculo familiar, de acordo com uma progressão paratáctica de desfile que simula a observação sequencial das fotografias de um álbum. Nelas reconhece o sujeito as personagens que povoaram essa "infância arcaica” (GUSMÃO, 2010, p. 470) que, a propósito de um outro verso da autora, refere Manuel Gusmão: "Reconheço a mãe" (JORGE, 2001, p. 71); "Reconheço o pai” (JORGE, 2001, p. 72); "E os avós são reis" (JORGE, 2001, p. 71). A opacidade referencial do texto de Luiza Neto Jorge, cuja lógica significante se desdobra ao ritmo de um fluxo imaginístico automático, de inspiração surrealista, aliada à "justaposição convulsiva de imagens em complexas redes analógicas, geradas, por exemplo, por relações paronímicas" (MARTELO, 2004, p. 167) - v.g. a sequência "cava”, "cova", "escava" -, tornam improdutiva qualquer tentativa de recomposição linear de uma crónica de família. A desfamiliarização do real ${ }^{15}$, para a qual concorrem tanto o estranhamento semântico como o deslassamento do tecido textual, não torna, contudo, irreconhecíveis as linhas isotópicas já antes rastreadas e conexionáveis com a inscrição poética do paradigma fotográfico, designadamente a reflexão sobre a usura do tempo e a ação desvirtuante da memória ou a instabilização da verdade referencial da fotografia. Sucedendo-se em entomológico cortejo no álbum, os antepassados parecem, paradoxalmente, "mais antigos/ mortos do que nós/ mais vivos mais sós” (JORGE, 2001, p. 72). Por outro lado, nesse exercício paroxístico e quase abjecionista de exumação dos espetros familiares, o poema amplia obsessivamente um núcleo simbólico-imagístico que conota os processos de desvanecimento, decomposição e descoloração das fotografias:

O que resta é hoje

o pouco o quase o fosco

relâmpago de um pescoço 
O álbum desfazia-se

porque um bicho o roía

com a família engrossava

da carne outra família (...)

O álbum tingiu da cor

que no longe não difere

muito da baba do bicho

ou do sangue da mulher (JORGE, 2001, p. 73-74).

4.

Noutros casos, a relação entre texto fotográfico e texto poético é de natureza assumidamente ecfrástica, como acontece com as sequências "Fragmentos de um discurso contemplativo", de Fernando Pinto do Amaral, ou "giraldomachias. onze poemas e um labirinto sobre fotografias de gérard castelo-lopes", de Vasco Graça Moura. No primeiro caso, o clin d'oeil barthesiano do título preludia o que, nos poemas conglutinados em políptico, pressupõe uma lógica sintática decalcada da découpage visual. A epígrafe de Yves Bonnefoy adverte para o falso jogo mimético concitado pelo registo fotográfico que, mesmo quando adota a máscara ilusoriamente translúcida de espelho do mundo, não deixa de ceder à tentação de transfiguração onírica ou subjetiva. A leitura do conjunto permite compreender até que ponto esta epígrafe constitui uma carta de intenções poética. Com efeito, embora os títulos dos poemas reenviem, sem exceção, para nomes de fotógrafos célebres, sobretudo nos domínios da moda ou do star system de Hollywood ${ }^{16}$ - Gregory Heisler, Steven Meisel, Mathew Rolston, Andrew MacPherson, Firooz Zahedi -, em nenhum deles se torna inequívoca a relação ecfrástica com um antetexto fotográfico singular - o que explica, aliás, no volume da Poesia Reunida, a ausência das fotografias de que, supostamente, eles constituiriam a legenda verbal. A atenuação da relação de ancilaridade intersemiótica entre texto fotográfico e texto verbal traduz-se, neste caso, na superação do estrito pictoralismo que caracteriza a ekphrasis descritiva e na nítida opção pelas suas modalidades interpretativa e dramática ${ }^{17}$. Em "Steven Meisel - II", por exemplo, a praeteritio do pictoralismo é justificada pelo fracasso previsível de todo o empreendimento descritivo, numa formulação onde parece ecoar a tópica clássica da competição interartes (paragone):

Volátil, o teu rosto

concentra-se por vezes sob o peso

imaterial das páginas: envoltas

pelos ágeis cabelos que flutuam

frágeis, as linhas

da face recomeçam a traçar

o mais perfeito mapa - descrevê-lo

só valeria a pena se a linguagem

pudesse atravessar a nitidez

do papel, o seu brilho (...)

(AMARAL, 2000, p. 303) 
Os poemas de Fernando Pinto do Amaral documentam, assim, muito para além da intenção mimético-replicativa do referente visual que convencionalmente informa a retórica da ekphrasis, a interlocução criativa do observador com aquelas que são as suas afinidades eletivas fotográficas $^{18}$, num fenómeno de nivelamento voyeuristico do real já salientado por Susan Sontag que lembra que "taking photographs has set up a chronic voyeuristic relation to the world which levels the meaning of all events" (SONTAG, 2008, p. 11). Essa vocação interlocutiva encontra, aliás, a sua expressão funcional no modelo elocutório que predomina nos poemas, invariavelmente marcados pela intensidade performativa do diálogo in $a b$ sentia que o sujeito entabula com o tu-protagonista da ficção fotográfica:

\author{
Sempre me interroguei porque te agrada \\ vestir de vez em quando algumas roupas \\ do outro sexo: o que daí resulta \\ não é um ar andrógino, mas sim \\ uma secreta dúvida que voa \\ e foge e rodopia sobre ti, \\ como se até a pose bem estudada \\ para a fotografia \\ não conseguisse aprisionar o caos. \\ (AMARAL, 2000, p. 304)
}

Embora se trate ainda de escrita ecfrástica, As Giraldomachias, de Vasco Graça Moura, colocam questões de natureza interpretativa substancialmente distintas. Com efeito, os poemas foram compostos no âmbito de um projeto anterior de colaboração com o fotógrafo Gérard Castello-Lopes, convidado pelo poeta a evocar ou ecoar "em imagens, os temas, o clima, os leit-motiv ou as obsessões" (CASTELLO-LOPES \& MOURA, 2000, p. 114) da sua obra. Na sequência do repto que lhe foi lançado por Graça Moura, propôs o fotógrafo que fosse, num segundo momento, o poeta a compor textos sobre fotografias suas. Este exercício consistiria, como argumenta Gérard Castello-Lopes, na

(...) interpretação de uma interpretação ou, em termos matemáticos, numa segunda derivada: o poeta interpreta uma realidade no seu poema, o fotógrafo interpreta o poema e dá-lhe uma "realidade" visual que, mesmo sem ser exactamente justaponível à que exprime o poeta, poderá (deverá?) ter com ela, um ar de família. Tudo está em tudo. (CASTELLO-LOPES \& MOURA, 2000, p. 114-115)

As variações poéticas de Graça Moura sobre as imagens de Gérard Castello-Lopes - que, no volume da sua poesia, aparecem injustificadamente amputadas das fotografias que, na edição original, as acompanhavam - são, assumidamente, "interpretação de uma interpretação", mantendo, contudo, com o texto icónico matricial uma relação de estreita cumplicidade. Sem deixarem de recuperar poeticamente o universo deí- 
tico das imagens que as acompanham - delas resgatando pessoas, objetos ou paisagens, até com expressa indicação toponímica -, as giraldomachias expandem, de forma rendosa, o capital semântico das imagines agentes de que partem, seja pela transfiguração lírica ("marvão", "bucólica insular"), pela comédia social, pela diatribe paródica ("os três velhos", "desforra") ou pela conjetura narrativa ("poema social"). Configuram, pois, maneiras de interpretação, como admite Castello-Lopes, num texto de apresentação que adequadamente intitulou "Hermenêuticas":

(...) a fotografia, tal como a entendo, só pode ser considerada como ficção, do mesmo modo que o romance, a pintura, a poesia e a sonata são ficções. E se a ficção se caracteriza como a interpretação pessoal duma realidade exterior ou interior, torna-se evidente que quem a contempla prolonga, em termos pessoais, essa interpretação do artista. (CASTELLO-LOPES \& MOURA, 2000, p. 114).

Ficção do mundo, a fotografia é - mais ainda, quando liricamente enquadrada - ficção de si - e o mesmo é dizer arte da pose ou triunfo do simulacro. Como poderiam, então, ser cândidas as fotografias reveladas na câmara escura da poesia?

\section{REFERÊNCIAS BIBLIOGRÁFICAS}

AL BERTO, O Medo. Lisboa: Contexto/Círculo de Leitores, 1991.

ÁLVARES, Cristina. Photographie et Écriture: la représentation en question. Ariane. revue deétudes littéraires françaises ("Le Cercle des Muses. O diálogo das artes II”). Vol. 17, p. 255-271, 2001-2002.

AMARAL, Fernando Pinto do. Poesia Reunida 1990-2000. Lisboa: Publicações Dom Quixote, 2000.

AMARAL, Ana Luísa. Poesia Reunida 1990-2005. Vila Nova de Famalicão: Edições quasi, 2005.

BAPTISTA, José Agostinho. Biografia. Lisboa: Assírio \& Alvim, 2000.

BARTHES, Roland. A Câmara Clara. Trad. de Manuela Torres. Lisboa: Edições 70, 2010.

BELO, Ruy. Todos os Poemas. Lisboa: Assírio \& Alvim, 2000.

BENJAMIN, Walter. Petite historie de la photographie. Oeuvres. Tome II. Paris: Gallimard, p. 295-321, 2000.

CARMELO, Carmelo. A Novíssima Poesia Portuguesa e a Experiência Estética Contemporânea. Mem Martins: Publicações Europa-América, 2005.

EIDT, Laura M. Sager. Writing and Filming the Painting. Ekphrasis in Literature and Film. Amsterdam-New York: Rodopi, 2008. 
GUSMÃO, Manuel. Tatuagem \& Palimpsesto. Da poesia em alguns poetas e poemas. Lisboa: Assírio \& Alvim. 2010.

JÚDICE, Nuno. Cartografia de Emoções. Lisboa: Publicações Dom Quixote, 2001.

. As coisas mais simples. Lisboa: Publicações Dom Quixote, 2006.

. Nuno. Guia de Conceitos Básicos. Lisboa: Publicações Dom

Quixote, 2010.

LOPES, Helena. Talvez as fotografias vagamente desfocadas/ sejam as mais belas - Poesia e media visuais em José Mário Silva e José Rui Teixeira. Jovens Ensaístas Lêem Jovens Poetas. Porto: Deriva Editores, p. 107-122, 2008.

MARTELO, Rosa Maria. Em Parte Incerta. Estudos de Poesia Portuguesa Moderna e Contemporânea. Porto: Campo das Letras, 2004.

MENDONÇA, José Tolentino. A noite abre meus olhos [poesia reunida]. Lisboa: Assírio \& Alvim, 2006.

MENEZES, Antonio Carlos Martins. Fotografia na poesia de Carlos Drummond de Andrade e Ruy Belo: transporte no tempo. Dissertação de mestrado em Literatura Brasileira e Teoria da Literatura. Niterói: Instituto de Letras-Universidade Federal Fluminense, 2006.

MEXIA, Pedro. Menos por Menos. Lisboa: Publicações Dom Quixote, 2011.

MOURA, Vaco Graça. Poesia 1997-2000. Lisboa: Quetzal Editores.

REVERSEAU, Anne. Métamorphoses du regard poétique: Réponses de la poésie descritive à l'époque moderniste. Écritures de la modernité, 2008. (disponível em http://www.ecritures-modernite.eu/?page_id=1953).

REVERSEAU, Anne. Breton, Man Ray et l'imaginaire photographique de la magie. textimage. Revue détude du dialogue texte-image.Varia 2, Été 2010. (disponível em http://www.revue-textimage.com/05_varia_2/ reverseaul.html).

RIBEIRO, Eunice. A hipótese da realidade: sobre o Laocoonte. Relâmpago, no 23, p. 145-162, outubro de 2008.

ROSA, João Carvalho Ribeiro Trinité. Porque tiramos fotografias? Dissertação de mestrado em Teoria da Literatura. Lisboa: Faculdade de Letras-Universidade de Lisboa. 2008.

SAMPAIO, Fernando Luís. Escadas de Incêndio. Lisboa: Quetzal, 2000.

SERRA, Pedro. Um nome para isto: leituras da poesia de Ruy Belo. Coimbra: Angelus Novus, 2004. 
SILVA, Denise Grimm da. Olhos que viram: visualidade e paisagem na poesia de Ruy Belo e Álvaro de Campos. Abril. Revista do Núcleo de Estudos de Literatura Portuguesa e Africana da UFF. Vol. 2, n. 2, p. 42-57, abril de 2009.

SONTAG, Susan. On Photography. London: Penguin, 2008.

Recebido para publicação em 28/03/12.

Aprovado em 15/05/2012.

\section{NOTAS}

1 Como, aliás, embora concedendo intencional precedência ao medium cinematográfico, demonstra o estimulante ensaio de Helena Lopes intitulado "Talvez as fotografias vagamente desfocadas/ sejam as mais belas - Poesia e media visuais em José Mário Silva e José Rui Teixeira" (2008).

2 Acolho aqui a noção de "imaginário fotográfico", nos termos em que a esclarece Anne Reverseau: "Le terme d'«imaginaire photographique (...) désigne l'imaginaire du medium à l'oeuvre dans les textes, c'est-à-dire la façon dont une technique d'enregistrement et de diffusion, en l'occurrence ici l'enregistrement visuel par coupe dans le temps et dans l'espace et la reproduction de cette image - l'ensemble du dispositif photographique joue dans les textes. Il ne s'agit donc pas d'étudier un soi-disant 'style photographique', mais plutôt la façon dont le poète envisage la photographie ainsi que son imaginaire littéraire, marqué par la photographie". Partindo desta dilucidação liminar, a autora rastreia, no início do século XX, a coexistência de três modalidades de imaginário fotográfico que designa respetivamente como técnico, documental e mágico. (REVERSEAU, 2010, s.p.)

3 Sobre a fecunda relação da poética de Ruy Belo com a estética fotográfica, podem lerse, com proveito, a análise deste e de outros textos do autor desenvolvida por Antonio Carlos Martins Meneses (2006) e Denise Grimm da Silva (2009).

4 Susan Sontag acentua, nos seguintes termos, a natureza elegíaca da fotografia: "Photography is an elegiac art, a twilight art. Most subjects photographed are, just by virtue of being photographed touched with pathos. (...) All photographs are memento mori. To take a photograph is to participate in another person's (or thing's) mortality, vulnerability, mutability. Precisely by slicing out this moment and freezing it, all photographs testify to time's relentless melt"; "Such images [images taken by cameras] are indeed able to usurp reality because first of all a photograph is not only an image (as a painting is an image), an interpretation of the real; it is also a trace, something directly stenciled off the real, like a footprint or a death mask"; "Photography is the inventory of mortality. A touch of the finger now suffices to invest a moment with posthumous irony. Photographs show people being so irrefutably there and at a specific age in their lives; group together people and things which a moment later have already disbanded, changed, continued along the course of their independent destinies". (SONTAG, 2008, p. 15; 54; 70)

5 Como salienta Barthes, “(...) o que constitui a natureza da Fotografia é a pose. (...) ao contemplar uma foto, incluo fatalmente no meu olhar o pensamento desse instante, por muito breve que tenha sido, em que uma coisa real ficou imóvel diante do olho. Faço recair a imobilidade da foto presente no «disparo» passado, e é essa paragem que constitui a pose" (BARTHES, 2010, p. 88)

$6 \mathrm{O}$ poema, inicialmente dado à estampa no $\mathrm{n}^{\circ} 2$ da revista Inútil (abril de 2010), era, na sua versão original, acompanhado da reprodução da fotografia de Eugène Atget, tendo posteriormente sido incluído em Guia de Conceitos Básicos (2010). 
7 A observação de João Carvalho Rosa sobre o poder mnemónico da narratio fotográfica pode, com propriedade, aplicar-se a este texto de Pedro Mexia: "À partida, as fotografias podem isoladamente fazer-nos recordar (por exemplo: uma fotografia pendurada numa parede, na mesa do escritório) mas a sua eficácia aumenta se por meio de uma articulação narrativa construirmos um relato documental - onde são acrescentados nomes, lugares, etc.". (ROSA, 2008, p. 44)

8 A expressão é utilizada por João Carvalho Rosa, para designar "o caso do típico conjunto de fotografias na mesinha da sala ou na parede". Cf. ROSA, 2008, p. 14.

9 Num outro poema de Pedro Mexia intitulado “Avó Leonor”, um mesmo efeito de trucagem fotográfica manifesta-se na aparição fantástica e inquietante de uma sombra ominosa que, "como uma coroa de trevas/ na máscara fúnebre" (MEXIA, 2011, p. 39), se abate, na fotografia, sobre a cabeça da avó já desaparecida: "E as rugas, o cabelo branco,/ o rosto de despedida/ são coroados por essa sombra/ que cresce/ de forma quase assustadora,/ como a alma de partida (...)" (MEXIA, 2011, p. 40).

10 A propósito do não-dito fotográfico como espaço de interpelação hermenêutica, observa Crsitina Álvares que “(...) la photo ne vise pas à la complétude iconique ni á la saturation sémantique: elle aplatit, désinvestit, met entre parenthèses les lois de fonctionnement des réseaux d'images, de discours, de conventions, de normes, de styles, de valeurs qui constituent l'automaton de la réalité. Contrairement à la belle image, sémantiquement épaisse et saturée, la photo se caractérise par une prédisposition à travailler contre la plénitude du champ perceptif. Elle ne le nie ni ne le troue mais, disons, remplace sa substance colorée par la platitude du noir et blanc" (ÁLVARES, 2001-2002, p. 258).

11 É precisamente essa tentativa persistente de fazer falar a fotografia, muito para além da intenção original do seu autor, que, segundo Susan Sontag, investe o registo fotográfico de uma crescente qualidade aurática, eximindo-o, inversamente ao que acontece com a pintura, à usura do tempo: "The real difference between the aura that a photograph can have and that of a painting lies in the different relation to time. The depredations of time tend to work against paintings. But part of the built-in interest of photographs, and a major source of their aesthetic value, is precisely the transformations that time works upon them, the way they escape the intentions of their makers. Given enough time, many photographs do acquire an aura" (SONTAG, 2008, p. 140).

12 Sobre os procedimentos de edição do real implicados pela sintaxe fotográfica, bem como a noção de fotografia como recorte cf. as seguintes reflexões de John Szarkowski reproduzidas, em apêndice, na obra de Susan Sontag: "Photography is a system of visual editing. At bottom, it is a matter of surrounding with a frame a portion of one's cone of vision, while standing in the right place at the right time. Like chess, or writing, it is a matter of choosing from among given possibilities, but in the case of photography the number of possibilities is not finite but infinite". (SONTAG, 2008, p. 192)

13 Adoto aqui a designação proposta por Walter Benjamin, para quem a fotografia "nous renseigne sur cet inconscient visuel, comme la psychanalyse nous renseigne sur l'inconscient pulsionnel." (BENJAMIN, 2000, p. 301).

14 Sobre o parentesco da gramática estética surrealista com a criação fotográfica, cf. as seguintes palavras de Susan Sontag: "Surrealism lies at the heart of the photographic enterprise: in the very creation of a duplicate world, of a reality in the second degree, narrower but more dramatic than the one perceived by natural vision." (SONTAG, 2008, p. 52)

15 Refletindo sobre o poder de desfamilizarização e desautomatização da fotografia, refere Susan Sontag que "photography, which has so many narcissistic uses, is also a powerful instrument for depersonalizing our relation to the world; and the two uses are complementary. Like a pair of binoculars with no right or wrong end, the camera makes exotic things near, intimate; and familiar things small, abstract, strange, much farther away. It offers, in one easy, habit-forming activity, both participation and alienation in our lives and those of others - allowing us to participate, while confirming alienation." (SONTAG, 2008, p. 167) 
16 A inclinação culturalista que caracteriza a poética de Fernando Pinto do Amaral ignora, regra geral, em bom magistério pós-moderno, as fronteiras artificiais que separam culto e popular, repondo o livre-trânsito entre ambos os territórios e reivindicando a cidadania literária de expressões de cultura highbrow e light.

17 Recupero a tipologia dos usos ecfrásticos proposta por Laura Sager Eidt que distingue as categorias da ekphrasis descritiva, interpretativa e dramática. No primeiro caso, "images are discussed, described, or reflected on more extensively in the text or scene, and several details or aspects of images are named and in the film shown in close-ups, zooms, and with slow camera movements". A ekphrasis interpretativa constitui "either (...) a verbal reflection on the image, or a visual-verbal dramatization of it in a mise-en-scène tableau vivant" e, neste contexto, "the image may function as a springboard for reflections that go beyond its depicted theme". Finalmente, no caso da modalidade dramatica, "the images are dramatized and theatricalized to the extent that they take on a life of their own”. (EIDT, 2008, p. 47; 50-51; 56).

18 Como salienta Eunice Ribeiro, “(...) o trabalho da écfrase na poesia contemporânea encaminha-se com frequência para uma prática abortiva que ocorre segundo padrões assumidamente antidescritivos ou metadescritivos, prescindindo não apenas de referência precisa, mas porventura desenvolvendo-se por remoção de referência e por proscrição da visão (...). O que poderá explicar, por um lado, o convívio recorrente do ecfrástico com o muito breve, com o instantâneo (demitidas clássicas pretensões e prescrições de exaustividade e inventário) e seu enlace com poéticas minimalistas de condensação e silêncio". (RIBEIRO, 2008, p. 149-150). 